Check for updates

Cite this: RSC Adv., 2017, 7, 53203

Received 25th August 2017

Accepted 11th November 2017

DOI: 10.1039/c7ra09434e

rsc.li/rsc-advances

\section{The solid-phase extraction of $\alpha$-chymotrypsin based on a novel porous polymeric dianionic ionic liquid-coated magnetic material $\uparrow$}

\author{
Qin Yang, Yuzhi Wang, (D) * Hongmei Zhang, Kaijia Xu, Xiaoxiao Wei, Jing Chen \\ and Panli Xu
}

\begin{abstract}
A novel magnetic solid-phase extraction (MSPE) method based on carboxymethylcellulose sodium modified $\mathrm{Fe}_{3} \mathrm{O}_{4}$ nanocomposite coated with porous polymeric dianionic ionic liquid ( $\mathrm{Fe}_{3} \mathrm{O}_{4}$ (aCMC(aPPDIL) was proposed and applied to extracting $\alpha$-chymotrypsin. The synthesized $\mathrm{Fe}_{3} \mathrm{O}_{4} \mathrm{QCMC}$ (aPPDIL was characterized by vibrating sample magnetometry (VSM), thermo-gravimetric analysis (TGA), transmission electron microscopy (TEM), X-ray diffraction (XRD), Fourier transform infrared spectrometry (FT-IR) and zeta potential measurement. Furthermore, the influence of a series of factors, such as extraction time and temperature, initial $\alpha$-chymotrypsin concentration, $\mathrm{pH}$ value and ionic strength, was systematically investigated. Under the optimal extraction conditions, the extraction capacity for $\alpha$-chymotrypsin could reach up to $122.91 \mathrm{mg} \mathrm{g}^{-1}$, and the activity of $\alpha$-chymotrypsin is well maintained after extraction. In addition, the proposed MSPE method provides satisfactory results in real sample analysis.
\end{abstract}

\section{Introduction}

Proteases play an irreplaceable role in the processes of life activities. ${ }^{\mathbf{1} 2}$ Chymotrypsin exists in vertebrates. ${ }^{3}$ As a typical serine proteolytic enzyme, it can selectively hydrolyze peptide bonds on the C-terminal side of tyrosine, phenylalanine, tryptophan and leucine at a fast speed. ${ }^{4}$ Compared with trypsin, $\alpha$-chymotrypsin possesses many superior properties such as stronger ability to hydrolyze proteins, lower toxicity, smaller adverse reactions and so on..$^{5-8}$ Therefore, it is of profound significance to develop a simple and effective pretreatment method to extract $\alpha$-chymotrypsin for further research.

On the basis of several conventional pretreatment methods like liquid-liquid extraction, ${ }^{9}$ solid-phase extraction ${ }^{\mathbf{1 0}}$ and solidphase microextraction, ${ }^{\mathbf{1 1}}$ a novel extraction method, called magnetic solid-phase extraction (MSPE), has been developed in the past few years. ${ }^{\mathbf{1 2 - 1 4}}$ The procedure of MSPE mainly includes two steps: adsorption and desorption. Firstly, the analyte in the sample solution is adsorbed by the magnetic extractant; secondly, the adsorbed analyte is eluted by a suitable eluent from the magnetic extractant. In this procedure, the magnetic extractant dispersed in the solution can be easily separated from the supernatant with the help of an external magnetic filed, which significantly simplifies the separation process.

State Key Laboratory of Chemo/Biosensing and Chemometrics, College of Chemistry and Chemical Engineering, Hunan University, Changsha, 410082, P. R. China. E-mail:wyzss@hnu.edu.cn; Fax:+86-731-88821848; Tel: +86-731-88821903

$\uparrow$ Electronic supplementary information (ESI) available. See DOI: 10.1039/c7ra09434e
Owing to a lot of outstanding advantages such as simple operation, less consumption of volatile organic solvents, high recovery, etc., many researchers have been attracted by this new technology. ${ }^{15-17}$

Owing to their ease to synthesize and low toxicity, magnetic $\mathrm{Fe}_{3} \mathrm{O}_{4}$ nanoparticles are usually adopted to offer extractants with magnetism in MSPE method. ${ }^{18-20}$ However, aggregation often occurs to nanoparticles, ${ }^{21}$ so a protective layer is needed. Carboxymethylcellulose sodium (CMC) is a carbohydratederived biomaterial, ${ }^{22}$ which is of good biocompatibility, biodegradability, low cost and non-toxicity. ${ }^{23}$ Thus, it can not only protect $\mathrm{Fe}_{3} \mathrm{O}_{4}$ nanoparticles from aggregation, but also promote the biocompatibility to coat $\mathrm{Fe}_{3} \mathrm{O}_{4}$ with CMC, which makes it more suitable for the analysis of biomass.

Ionic liquid (IL) possesses plenty of excellent properties such as electrochemical and thermal stability, low volatility, nonflammability and so forth, which make it be regarded as "green solvents". Polymeric ionic liquid (PIL) is a further development of IL. ${ }^{24,25}$ PIL is equipped with the most useful properties of IL. Meanwhile, it possesses the superior properties of polymers, such as elasticity, plasticity, corrosion resistance and so forth. ${ }^{26}$ As a result, the combination of PIL and MSPE method shows great attractivity and significance in the filed of biomolecules analysis.

In this work, carboxymethylcellulose sodium modified $\mathrm{Fe}_{3} \mathrm{O}_{4}$ nanocomposite coated with porous polymeric dianionic ionic liquid ( $\left.\mathrm{Fe}_{3} \mathrm{O}_{4} @ \mathrm{CMC} @ P P D I L\right)$ was synthesized and applied to the extraction for $\alpha$-chymotrypsin ( $\alpha$-Chy) coupled with MSPE method for the first time. The extraction performance of $\mathrm{Fe}_{3}$ $\mathrm{O}_{4} @$ @MC@PPDIL was further investigated and optimized. 
Moreover, the activity of $\alpha$-chymotrypsin eluted from extractant was tested. And the proposed method was successfully applied to the real sample analysis.

\section{Experimental}

\subsection{Reagents and apparatuses}

All reagents used in this work were analytical grade without any further purification. $\mathrm{FeCl}_{3}, \mathrm{FeCl}_{2} \cdot 4 \mathrm{H}_{2} \mathrm{O}$, hydrazine hydrate, sodium hydroxide $(\mathrm{NaOH})$, carboxymethylcellulose sodium (CMC), sodium dodecyl sulfate (SDS) and itaconic acid were bought from Sinopharm Chemical Teagent Co., Ltd. (Shanghai, China). Choline, $\alpha$-chymotrypsin ( $\alpha$-Chy) from porcine pancreas, bovine serum albumin (BSA), ovalbumin (OVA), lysozyme (Lys) and bovine hemoglobin (BHb) were supplied by Shanghai yuanye Bio-Technology Co., Ltd. (China). $N$-Benzoyl-L tyrosine ethyl ester (BTEE) was gained from J\&K Chemical Technology Co. Ltd. (Beijing, China). Acrylic acid, $N, N$-methylenebisacrylamide (MBAA) and ammonium persulfate (APS) were purchased from Fucheng Chemicals (Tianjin, China). The water utilized throughout the research was ultra pure water.

The main apparatuses were listed below: B-220 thermostat water bath (Shanghai, China); UV-2450 UV-vis spectrophotometer (Shimadzu, Japan); STA409 thermal gravimetric analyzer (TGA, Netzsch, Germany); DZF-6051 vacuum drying oven (Shanghai, China); FT-IR spectrometer (PerkinElmer, USA); KQ 3200E ultrasonic cleaner (Kunshan ultrasonic instruments Co., Ltd., China); STA 409 thermal gravimetric analyzer (Netzsch, Germany); EV 11 Vibrating Sample Magnetometer (MicroSense, USA); HT-7700 transmission electron microscope (TEM, Hitachi, Japan); QWC200 incubator shaker (Shanghai, China); INOVA 400NB NMR (Varian, America).

\subsection{Preparation of $\mathrm{Fe}_{3} \mathrm{O}_{4} @ \mathrm{CMC}$}

According to the literature, ${ }^{27,28}$ the CMC-modified $\mathrm{Fe}_{3} \mathrm{O}_{4}$ nanoparticles $\left(\mathrm{Fe}_{3} \mathrm{O}_{4} @ \mathrm{CMC}\right)$ were synthesized by chemical coprecipitation method with slight modification. $0.5 \mathrm{~g}$ of CMC was dissolved in $50 \mathrm{~mL}$ of water. Subsequently, $4.86 \mathrm{~g} \mathrm{of} \mathrm{FeCl}_{3}$ and $3.98 \mathrm{~g}$ of $\mathrm{FeCl}_{2} \cdot 4 \mathrm{H}_{2} \mathrm{O}$ were added into the solution and dissolved with mechanical stirring $\left(400 \mathrm{rpm} \mathrm{min}^{-1}\right)$ at room temperature, followed by the addition of $1 \mathrm{~mL}$ of hydrazine hydrate. Next, the mixture was heated to 60 degrees celsius in water bath and appropriate amount of $\mathrm{NaOH}$ solution was poured into the reaction solution to adjust the $\mathrm{pH}$ value to 11 . The $\mathrm{Fe}_{3} \mathrm{O}_{4} @ \mathrm{CMC}$ was synthesized after stirring at $400 \mathrm{rpm} \min ^{-1}$ for $30 \mathrm{~min}$. The resulting mixture was washed by water and ethanol for several times and dried under vacuum at 50 degrees celsius to obtain the final product.

\subsection{Preparation of DIL-monomer}

The dianionic IL-monomer was synthesized by one-step method referred to the literature. ${ }^{29}$ The synthetic route is shown in Fig. 1. Itaconic acid and choline $(1: 2)$ reacted in water solution at room temperature, stirring at a speed of $400 \mathrm{rpm} \mathrm{min}^{-1}$ for $12 \mathrm{~h}$. The water was then removed by rotate evaporation and vacuum drying. The ${ }^{1} \mathrm{H}$ NMR spectra of the IL-monomer is as follows: (500 MHz, DMSO-d 6 ) $\delta 5.49(\mathrm{~d}, J=3.9 \mathrm{~Hz}, 1 \mathrm{H}), 4.91$ (d, $J=3.9 \mathrm{~Hz}, 1 \mathrm{H}), 4.07-3.66(\mathrm{~m}, 4 \mathrm{H}), 3.60-3.24(\mathrm{~m}, 4 \mathrm{H}), 3.12$ (s, 18H), $2.83(\mathrm{~s}, 2 \mathrm{H}), 2.49(\mathrm{~s}, 2 \mathrm{H})$.

\subsection{Preparation of extractants}

Three kinds of polymeric ionic liquid-based extractants, $\mathrm{Fe}_{3}$ $\mathrm{O}_{4}$ @CMC coated with porous polymeric dianionic ionic liquid ( $\mathrm{Fe}_{3} \mathrm{O}_{4}$ @CMC@PPDIL), $\mathrm{Fe}_{3} \mathrm{O}_{4} @ \mathrm{CMC}$ coated with polymeric dianionic ionic liquid $\left(\mathrm{Fe}_{3} \mathrm{O}_{4} @ \mathrm{CMC} @ P D I L\right)$ and $\mathrm{Fe}_{3} \mathrm{O}_{4} @ \mathrm{CMC}$ coated with polymeric dianionic ionic liquid and $\mathrm{CaCO}_{3}\left(\mathrm{Fe}_{3}-\right.$ $\mathrm{O}_{4}$ @CMC@PDIL/CaCO${ }_{3}$ ), were synthesized by seed emulsion polymerization $^{30}$ and templating ${ }^{31}$ method with some modification. Taking $\mathrm{Fe}_{3} \mathrm{O}_{4} @ \mathrm{CMC} @ P P D I L$ as an example, firstly, $0.5 \mathrm{~g}$ of $\mathrm{Fe}_{3} \mathrm{O}_{4} @ \mathrm{CMC}$ was treated with sonication for $20 \mathrm{~min}$ to disperse in $30 \mathrm{~mL}$ of ethanol. After that, $5 \mathrm{~mL}$ of acrylic acid was added into this suspension, followed by shaking for $1 \mathrm{~h}$ and then the resultant was washed with ethanol for several times and dispersed in $10 \mathrm{~mL}$ of ethanol. The resulting suspension was named as solution $\mathrm{A}$. On the other hand, $0.5 \mathrm{~mL}$ of IL-monomer and $0.5 \mathrm{~g}$ of $\mathrm{CaCO}_{3}$ were well mixed in $8 \mathrm{~mL}$ of water with the help of sonication for $20 \mathrm{~min}$, which was named as solution B. Afterwards, solution A and $10 \mathrm{mg}$ of SDS were dispersed in $40 \mathrm{~mL}$ of water, bubbled with nitrogen for $30 \mathrm{~min}$. Subsequently, solution $\mathrm{B}$ and $40 \mathrm{mg}$ of MBAA were added into the resulting mixture. After bubbled for another $20 \mathrm{~min}, 0.5 \mathrm{~mL}$ of APS solution $\left(20 \mathrm{mg} \mathrm{mL}^{-1}\right)$ was added, and the dispersion was heated to 75 degrees celsius in water bath to polymerize for $7 \mathrm{~h}$. The final product was washed with EDTA solution $(0.2 \mathrm{M})$, the $\mathrm{pH}$ value of which was adjusted to 7.5 with $\mathrm{NaOH}$, to remove $\mathrm{CaCO}_{3}$, and then with water and ethanol for several times and dried in vacuum drier overnight.

The synthetic routes of $\mathrm{Fe}_{3} \mathrm{O}_{4}$ @CMC@PDIL and $\mathrm{Fe}_{3} \mathrm{O}_{4} @$ $\mathrm{CMC} @ \mathrm{PDIL} / \mathrm{CaCO}_{3}$ were roughly the same with that of $\mathrm{Fe}_{3}$ $\mathrm{O}_{4} @$ @MC@PPDIL. The former material was prepared following the same procedure mentioned above without addition of $\mathrm{CaCO}_{3}$. As for the latter one, the step that the product was washed with EDTA solution was skipped. In other words, the $\mathrm{CaCO}_{3}$ wasn't removed.

\subsection{Magnetic solid-phase extraction procedure of analytes}

The synthesized extractants were applied in the MSPE of analytes (as shown in Fig. 2). Details are as follows. $5 \mathrm{mg}$ of

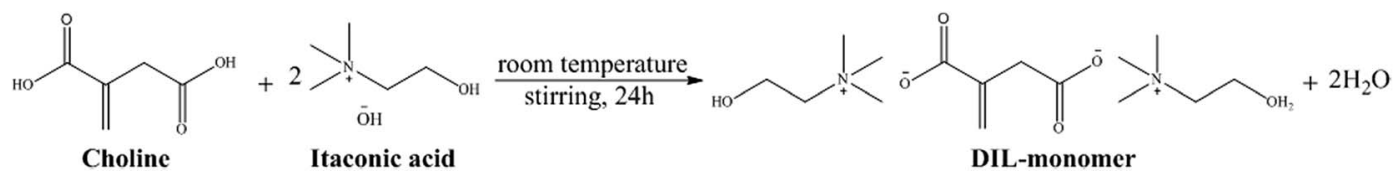

Fig. 1 Synthesis of DIL-monomer. 


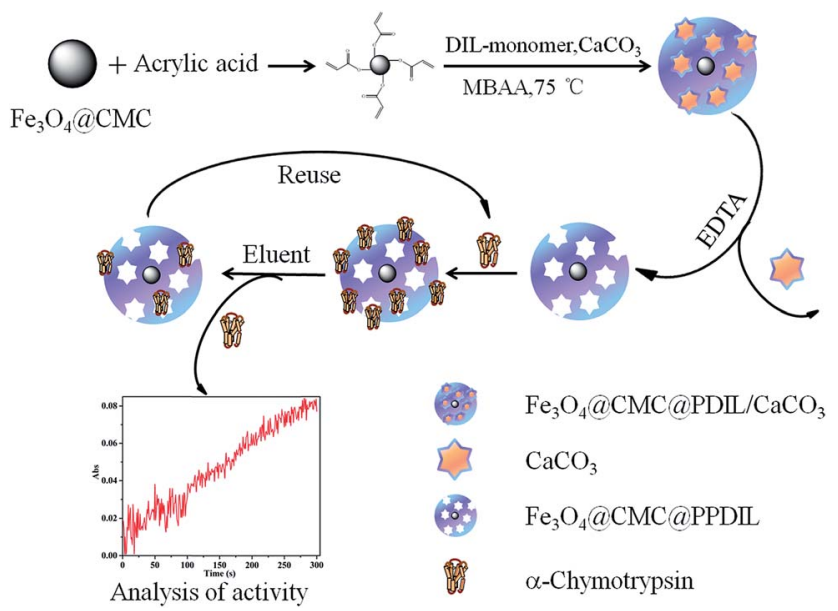

Fig. 2 Synthetic route of $\mathrm{Fe}_{3} \mathrm{O}_{4}$ @CMC@PPDIL and flow chart of its application in MSPE.

extractant was added into $1 \mathrm{~mL}$ of aqueous solution where the concentration of analyte was $1 \mathrm{mg} \mathrm{mL} \mathrm{m}^{-1}$. After shaken at constant temperature of 30 degrees celsius for $30 \mathrm{~min}$, the mixture was treated with a magnet at the bottom to obtain the supernatant. The concentrations of analyte in the supernatant and initial solution were detected by UV-vis spectrophotometer at corresponding wavelength, around $278 \mathrm{~nm}$ for $\alpha$-Chy, OVA, Lys and BSA and $404 \mathrm{~nm}$ for BHb. The extraction capacity $(Q)$ was evaluated according to the following formula: ${ }^{21}$

$$
Q=\frac{\left(C_{\mathrm{o}}-C\right) V}{m}
$$

where $C_{\mathrm{o}}$ and $C\left(\mathrm{mg} \mathrm{mL}^{-1}\right)$ represent the protein concentration of initial solution and extracted solution, respectively. $V(\mathrm{~mL})$ is the volume of the initial protein solution and $m(\mathrm{~g})$ is the mass of extractant.

\subsection{Analysis of $\alpha$-chymotrypsin activity}

The analysis of $\alpha$-chymotrypsin activity was carried out by BTEE method. At 25 degrees celsius, $1.40 \mathrm{~mL}$ of $\alpha$-chymotrypsin solution $(1.18 \mathrm{mM})$ was mixed with $1.42 \mathrm{~mL}$ of Tris-HCl buffer solution ( $\mathrm{pH}=7.8$ ). Subsequently, $0.08 \mathrm{~mL}$ of $\mathrm{CaCl}_{2}$ solution ( $2 \mathrm{M})$ was added into the mixture. After $0.10 \mathrm{~mL}$ of BTEE solution with suitable concentration, which was dissolved in $1 \mathrm{mM}$ of $\mathrm{HCl}$ solution, was added, the resulting mixture was shaken for several times and recorded the increase of absorbance at $256 \mathrm{~nm}$ for $5 \mathrm{~min}$ immediately. The activity of $\alpha$-chymotrypsin was described by the relative activity $\left(U_{\mathrm{r}}\right)$, which was calculated by the following formula: ${ }^{27}$

$$
U_{\mathrm{r}}=\frac{U_{\mathrm{e}}}{U_{\mathrm{n}}}
$$

where $U_{\mathrm{e}}$ is the BTEE unit of $\alpha$-chymotrypsin in the eluent and $U_{\mathrm{n}}$ is the BTEE unit of $\alpha$-chymotrypsin in the buffer solution with the same concentration.

\section{Results and discussion}

\subsection{Characterization of extractants}

3.1.1. Vibrating sample magnetometer. Magnetic studies by an EV 11 vibrating sample magnetometer show some changes in field-depended magnetization among the four kinds of materials (as shown in the ESI file Fig. S1†). Compared with $\mathrm{Fe}_{3} \mathrm{O}_{4}$ @CMC (43.52 emu $\mathrm{g}^{-1}$ ), the saturation magnetizations of $\mathrm{Fe}_{3} \mathrm{O}_{4} @ \mathrm{CMC} @ P P D I L\left(41.94\right.$ emu $\left.\mathrm{g}^{-1}\right), \mathrm{Fe}_{3} \mathrm{O}_{4} @$ CMC@PDIL (39.69 emu $\mathrm{g}^{-1}$ ) and $\mathrm{Fe}_{3} \mathrm{O}_{4} @ \mathrm{CMC} @ P D I L / \mathrm{CaCO}_{3}$ $\left(30.75 \mathrm{emu}^{-1}\right)$ are all a little smaller, which proves a side proof to the coating of polymer over $\mathrm{Fe}_{3} \mathrm{O}_{4} @ \mathrm{CMC}$. Although there is a slight decrease in the magnetism, it's strong enough to assure magnetic separation in extraction procedure from the illustration.

3.1.2. Thermo-gravimetric analysis. The synthesized extractants were all tested by a STA 409 thermal gravimetric analyzer to investigate the thermal stabilities. As shown in the ESI file Fig. S2, $\dagger$ when the test temperature rises to 1000 degrees celsius, the weight loss of $\mathrm{Fe}_{3} \mathrm{O}_{4} @ \mathrm{CMC}$ is $11.43 \%$, which is the result of removal of water and $\mathrm{CMC}$. Obviously, the weight losses of the three coated materials, $\mathrm{Fe}_{3} \mathrm{O}_{4}$ @CMC@PPDIL, $\mathrm{Fe}_{3} \mathrm{O}_{4} @ \mathrm{CMC} @ P D I L$ and $\mathrm{Fe}_{3} \mathrm{O}_{4} @ \mathrm{CMC} @ P D I L / \mathrm{CaCO}_{3}$, turn out to be more, $23.17 \%, 24.49 \%$ and $29.48 \%$, respectively. The more weight losses are ascribed to the decomposition of poly-ionic liquid and $\mathrm{CaCO}_{3}$ besides water and CMC, which proves successful modification over $\mathrm{Fe}_{3} \mathrm{O}_{4} @$ @MC.

3.1.3. Transmission electron microscope. The morphologies of these prepared materials were characterized by TEM (shown in Fig. 3). It can be seen that the size of particles in Fig. 3B-D are all larger than that in Fig. 3A, which evidences the growth of ionic liquid polymer or $\mathrm{CaCO}_{3}$ on $\mathrm{Fe}_{3} \mathrm{O}_{4}$ @CMC

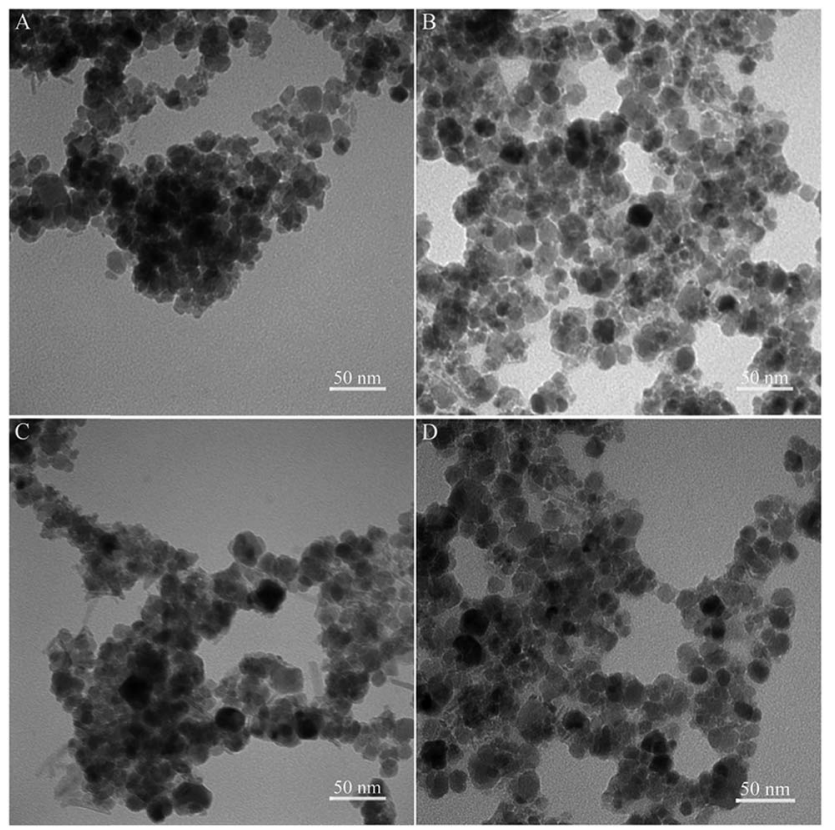

Fig. 3 TEM images of $\mathrm{Fe}_{3} \mathrm{O}_{4} \mathrm{aCMC}$ (A), $\mathrm{Fe}_{3} \mathrm{O}_{4}$ @CMCaPPDIL (B), $\mathrm{Fe}_{3} \mathrm{O}_{4} \mathrm{aCMC}\left(\mathrm{PPDIL}\right.$ (C) and $\mathrm{Fe}_{3} \mathrm{O}_{4} \mathrm{QCMC}\left(\mathrm{PPDIL} / \mathrm{CaCO}_{3}\right.$ (D). 
nanoparticles. What's more, compared with other three materials, porous structure appears in the TEM picture of $\mathrm{Fe}_{3} \mathrm{O}_{4} @$ CMC@PPDIL.

3.1.4. X-ray diffraction. The XRD patterns of the four kinds of extractants are shown in Fig. 4. Similar diffraction peaks, appearing at $2 \theta$ angle of $30.14^{\circ}(220), 35.52^{\circ}(311), 43.14^{\circ}(400)$, $53.50^{\circ}(422), 57.06^{\circ}(511)$ and $62.76^{\circ}(440)$, can be found in all the patterns, which confirms the existence of $\mathrm{Fe}_{3} \mathrm{O}_{4}$ (JCPDS 26-1136).

3.1.5. Fourier transform infrared spectrometry. A FT-IR spectrometer was utilized to analyze the chemical structure of the four types of extractants. As shown in the ESI file Fig. S3, $\dagger$ the characteristic stretching vibration peak of $\mathrm{Fe}-\mathrm{O}\left(575 \mathrm{~cm}^{-1}\right)$ can be observed in Fig. S3B-E, $\dagger$ which proves the successful synthesis of $\mathrm{Fe}_{3} \mathrm{O}_{4}$. The peak at $1396 \mathrm{~cm}^{-1}$ corresponds to the stretching vibration of $-\mathrm{COO}^{-}$. Furthermore, the stretching vibration peaks of $\mathrm{O}-\mathrm{H}, \mathrm{C}=\mathrm{C}$ and $\mathrm{C}-\mathrm{N}$ in ionic liquid appear at 3386, 1582 and $1052 \mathrm{~cm}^{-1}$, respectively, which provides evidence to the successful preparation of ionic liquid and polymerization over magnetic $\mathrm{Fe}_{3} \mathrm{O}_{4} @ \mathrm{CMC}$ composite. The peak at $880 \mathrm{~cm}^{-1}$ belongs to $\mathrm{CO}_{3}{ }^{2-}$ of $\mathrm{CaCO}_{3}$.

3.1.6. Isoelectric point. The isoelectric points (pI) were investigated by a zeta potentiometer in phosphate buffer solution with different $\mathrm{pH}$ values. As shown in the ESI file Fig. $\mathrm{S} 4, \uparrow$ compared with the pI of $\mathrm{Fe}_{3} \mathrm{O}_{4} @ \mathrm{CMC}$ (2.2), the pI of $\mathrm{Fe}_{3} \mathrm{O}_{4} @$ CMC@PPDIL rises to 2.7 and that of $\mathrm{Fe}_{3} \mathrm{O}_{4} @ \mathrm{CMC} @ P D I L$ and $\mathrm{Fe}_{3} \mathrm{O}_{4}$ @CMC@PDIL/CaCO 3 both increase to 2.5. The modification over $\mathrm{Fe}_{3} \mathrm{O}_{4} @ \mathrm{CMC}$ is verified by the change of pI. The differences among the pI values of these materials prepared in this work are indeed very small, which may be the result that the amount of the coating layer over magnetic particles is very little and the components of these materials are similar to each other.

\subsection{Comparison of extractants}

To certify the priority of the porous material in extraction performance, the four kinds of extractants $\left(\mathrm{Fe}_{3} \mathrm{O}_{4} @ \mathrm{CMC}\right.$, $\mathrm{Fe}_{3} \mathrm{O}_{4} @ \mathrm{CMC} @ P P D I L, \quad \mathrm{Fe}_{3} \mathrm{O}_{4} @ \mathrm{CMC} @ P D I L$ and $\mathrm{Fe}_{3} \mathrm{O}_{4} @$ CMC@PDIL/ $\mathrm{CaCO}_{3}$ ) were all applied to the MSPE procedure with the same operation as that described in section 2.5. In this

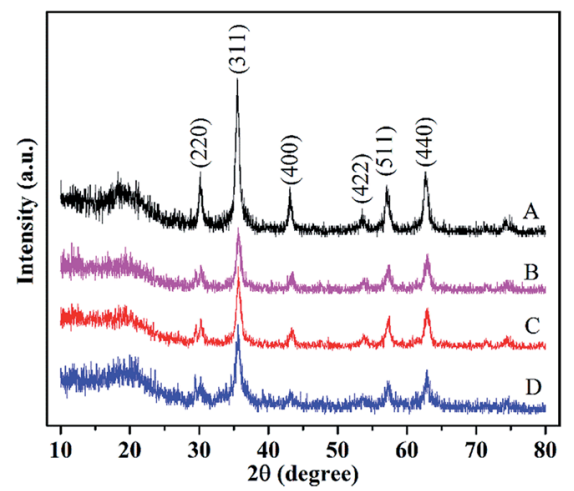

Fig. 4 XRD patterns of $\mathrm{Fe}_{3} \mathrm{O}_{4} \mathrm{aCMC}(\mathrm{A}), \mathrm{Fe}_{3} \mathrm{O}_{4}$ @CMCMPPDIL (B), $\mathrm{Fe}_{3} \mathrm{O}_{4} \mathrm{aCMC}\left(\mathrm{PPDIL}(\mathrm{C})\right.$ and $\mathrm{Fe}_{3} \mathrm{O}_{4} \mathrm{QCMC}\left(\mathrm{PPDIL} / \mathrm{CaCO}_{3}\right.$ (D).

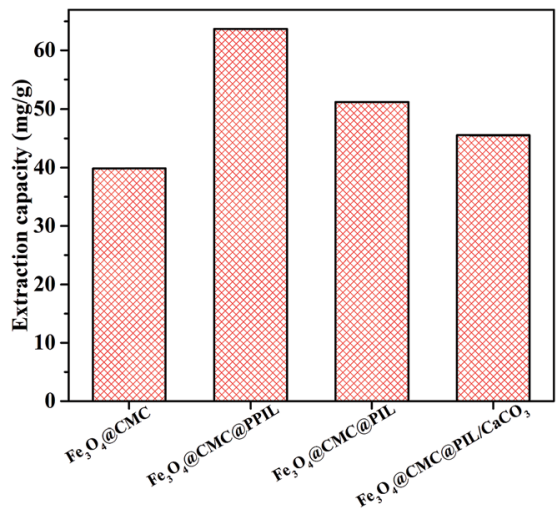

Fig. 5 Extraction abilities for $\alpha$-chymotrypsin of different extractants.

study, $\alpha$-Chy was selected as the target analyte. From Fig. 5, absolutely, all the three kinds of polymeric ionic liquid-based extractants extract more $\alpha$-Chy than $\mathrm{Fe}_{3} \mathrm{O}_{4} @ \mathrm{CMC}$, which proves that polymeric ionic liquid indeed promotes the extraction capacity for $\alpha$-Chy. It can be attributed that the hydroxyl groups and dianionic center in ionic liquid improves the interaction between extractants and $\alpha$-Chy, which causes the increase of the extraction properties of ionic liquid modified extractants compared with the unmodified extractant. Moreover, $\mathrm{Fe}_{3} \mathrm{O}_{4} @ \mathrm{CMC} @ P P D I L$ shows manifestly better extraction ability (63.68 $\mathrm{mg} \mathrm{g}^{-1}$ ) than the other three materials (39.84, 51.23 and $45.54 \mathrm{mg} \mathrm{g}^{-1}$ ). The porous structure of $\mathrm{Fe}_{3} \mathrm{O}_{4}$ @ CMC@PPDIL can provide more activity sites to interact with analyte, which contributes to the extraction ability. As a result, $\mathrm{Fe}_{3} \mathrm{O}_{4} @ \mathrm{CMC} @ P P D I L$ was selected in the next studies.

\subsection{Single factor experiments}

3.3.1. Effect of the initial concentration of $\alpha$-Chy. The initial concentration of analyte has influence on the extraction procedure. A group of experiments was carried out with $5 \mathrm{mg}$ of $\mathrm{Fe}_{3} \mathrm{O}_{4} @ \mathrm{CMC} @ P P D I L$, extraction time of $30 \mathrm{~min}$, temperature of 30 degrees celsius, and $\alpha$-Chy was dissolved in ultrapure water without addition of any salt. The influence of $\alpha$-Chy concentration in initial solution, ranging from 0.2 to $2.0 \mathrm{mg} \mathrm{mL}^{-1}$, was investigated. From Fig. 6A, the extraction capacity increases fast in the range of 0.2 to $1.0 \mathrm{mg} \mathrm{mL}^{-1}$ and keeps unchanged till the concentration is over $1.0 \mathrm{mg} \mathrm{mL} \mathrm{m}^{-1}$. This may be explained as that there is no more adsorption site to be available for $\alpha$-Chy when the concentration keeps increasing. Thus, $1.0 \mathrm{mg} \mathrm{mL}^{-1}$ of $\alpha$-Chy solution was utilized in the further study.

3.3.2. Effect of the extraction time. To investigate the effect of the extraction time on the extraction capacity, a series of experiments were carried out within a period of time (10-120 min). From Fig. 6B, it is easy to find that the extraction capacity of extractant for $\alpha$-Chy increases clearly until the extraction time reaches $40 \mathrm{~min}$. However, longer time seems to be no more beneficial to the extraction procedure. In other words, the extraction equilibrium is achieved within $40 \mathrm{~min}$ in this study. As a result, the extraction time in the following research was set as $40 \mathrm{~min}$. 

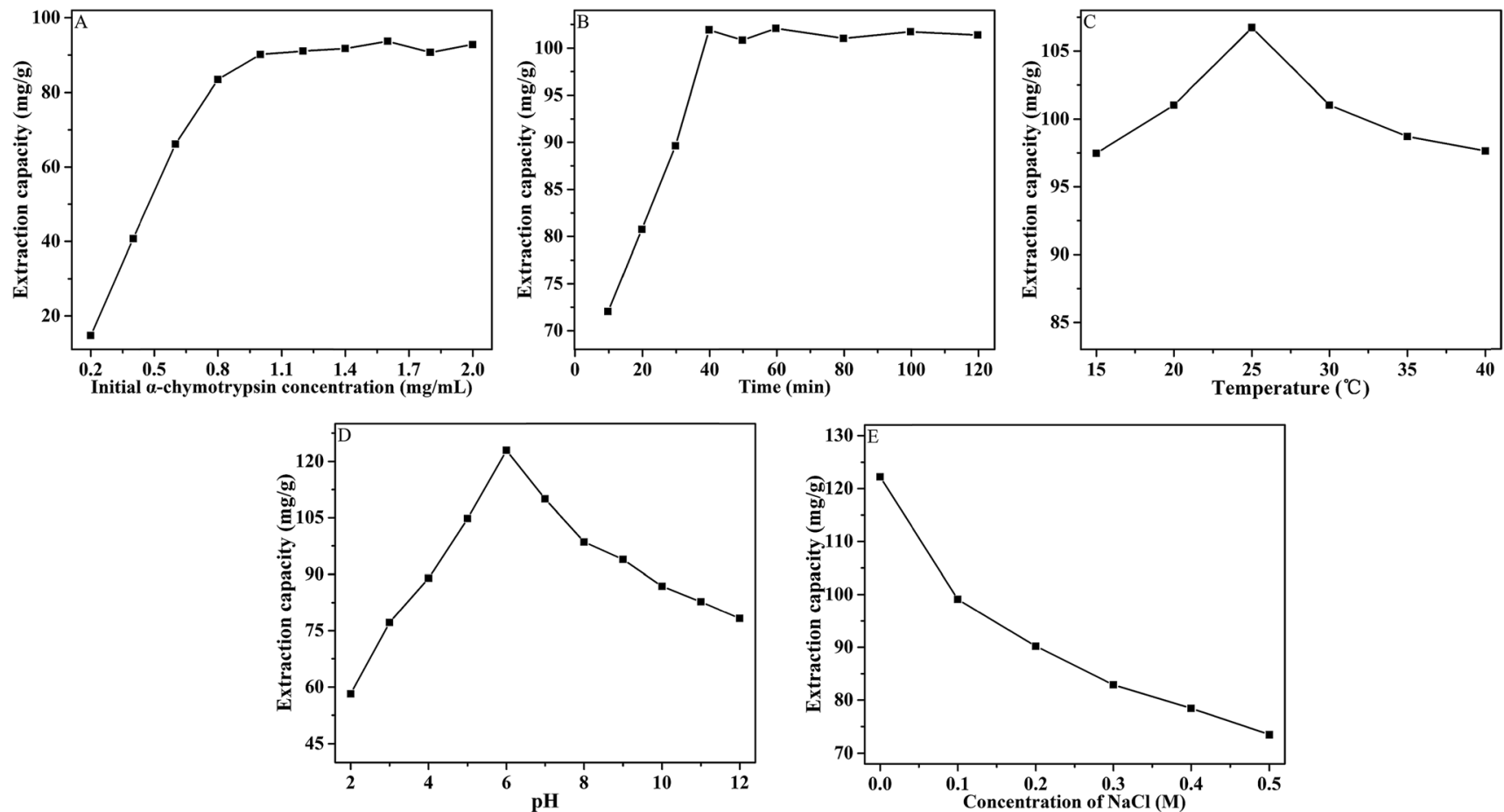

Fig. 6 Effect of initial $\alpha$-chymotrypsin concentration (A), extraction time (B), temperature (C), pH value (D) and ionic strength (E) on the extraction capacities.

3.3.3. Effect of the extraction temperature. As is known to all, experiment temperature may have impact on the extraction capacity. Researches on temperature were conducted from 15 to 40 degrees celsius. As can be seen from Fig. 6C, when the experiment temperature is 25 degrees celsius, the extraction capacity is the highest, compared with lower or higher temperature. Therefore, the next study was performed at 25 degrees celsius.

3.3.4. Effect of $\mathbf{p H}$ value. As the surface charges of proteins and solid-phase extractants are influenced sharply by the $\mathrm{pH}$ value of sample solution, the $\mathrm{pH}$ value plays an important role in the extraction procedure. A group of experiments were carried out to study the influence of $\mathrm{pH}$ value from 2 to 12 and the results are shown in Fig. 6D. Apparently, the crest value of extraction capacity is achieved at the solution $\mathrm{pH}$ value of 6 , which can be ascribed to the opposite external charges between $\alpha$-Chy ( $\mathrm{pI}=8.1$ ) and magnetic extractant $(\mathrm{pI}=2.7)$. The electrostatic attraction between them consumedly improves the extraction capacity. Accordingly, the MSPE procedure was conducted in buffer solution with $\mathrm{pH}$ value of 6 in the further research.

3.3.5. Effect of ionic strength. A series of sample solutions with concentrations of $\mathrm{NaCl}$ varying from 0 to $0.5 \mathrm{M}$ were utilized in MSPE procedure to investigate the impact of ionic strength. As shown in Fig. 6E, it's no doubt that the existence of $\mathrm{NaCl}$ makes against the extraction performance. The ion from $\mathrm{NaCl}$ competes with $\alpha$-Chy to be extracted by $\mathrm{Fe}_{3} \mathrm{O}_{4} @$ CMC@PPDIL nanomaterial, which reduces the extraction of $\alpha$-Chy onto $\mathrm{Fe}_{3} \mathrm{O}_{4} @$ @CMC@PPDIL. Thereby, no NaCl was adopted next.

\subsection{Comparison of extraction capacity on different analytes}

The synthesized $\mathrm{Fe}_{3} \mathrm{O}_{4} @ \mathrm{CMC}$ and $\mathrm{Fe}_{3} \mathrm{O}_{4} @ \mathrm{CMC} @ P P D I L$ nanomaterials were applied in the MSPE for several kinds of analytes, $\alpha$-Chy, BSA, OVA, Lys and BHb, to verify the extraction ability. It can be seen from Fig. 7 that all the five kinds of analytes can be extracted by the two kinds of extractants to different degrees. Typically, the extraction capacity of $\mathrm{Fe}_{3} \mathrm{O}_{4}$ @ CMC@PPDIL for $\alpha$-Chy (122.91 $\mathrm{mg} \mathrm{g}^{-1}$ ) is the highest among them. Thus, it can be promising to use $\mathrm{Fe}_{3} \mathrm{O}_{4} @ \mathrm{CMC} @ P P D I L$ as a novel extractant for $\alpha$-Chy.

\subsection{Analysis of $\alpha$-Chy activity}

The change of biological activity of analytes before and after pretreatment acts a crucial element to assess a pretreatment

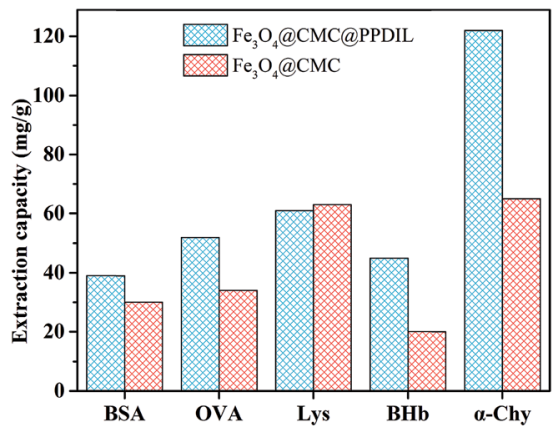

Fig. 7 Extraction for different proteins. 


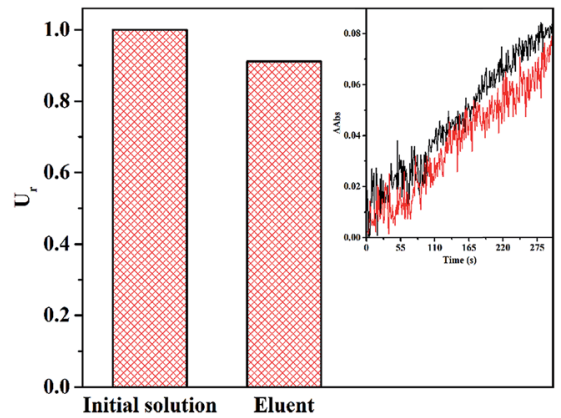

Fig. 8 Activity of $\alpha$-chymotrypsin in initial solution (A) and in eluent.

method. In this work, the extracted $\alpha$-Chy was eluted from $\mathrm{Fe}_{3} \mathrm{O}_{4}$ @CMC@PPDIL by phosphate buffer solution with pH value of 2 . Herein, both the activity of $\alpha$-Chy in the initial solution and eluent were tested, as shown in the illustration in Fig. 8. By calculation, the activity of $\alpha$-Chy in the eluent keeps $91.05 \%$ of initial activity. So it is inferred that the proposed MSPE method is effective to extract $\alpha$-Chy.

\subsection{Extraction stability, reproductivity and precision}

Fig. 9A shows the result of stability experiment. The $\mathrm{Fe}_{3} \mathrm{O}_{4} @$ CMC@PPDIL was synthesized and stored at room temperature and pressure. It was used in MSPE procedure every day within seven days to test the stability of this material. It's not difficult to find that there is no difference in extraction capacity as time goes by.

In addition, the $\mathrm{Fe}_{3} \mathrm{O}_{4} @ \mathrm{CMC} @ P P D I L$ nanocomposite was used for extraction and desorption repeatedly to study the reproductivity. The result in Fig. 9B shows that the extraction capacity for $\alpha$-Chy decreases slightly in the second cycle but keeps unchanged in the next several cycles, which is still a satisfactory value of $99 \mathrm{mg} \mathrm{g}^{-1}(81.15 \%$ of the initial extraction capacity).

Besides, the precision of the $\mathrm{Fe}_{3} \mathrm{O}_{4} @ C M C @ P P D I L-b a s e d$ MSPE method was also investigated. As shown in Table 1, the RSD turns out to be $0.33 \%$ in the experiments of precision, which provides a convincing proof that the proposed method is of excellent precision.
Table 1 The results of precision experiments

\begin{tabular}{|c|c|c|c|c|c|}
\hline Repeats & 1 & 2 & 3 & 4 & 5 \\
\hline Extraction capacity $\left(\mathrm{mg} \mathrm{g}^{-1}\right)$ & 121.49 & 120.95 & 120.78 & 120.42 & 121.13 \\
\hline $\operatorname{RSD}(\%)$ & 0.33 & & & & \\
\hline
\end{tabular}

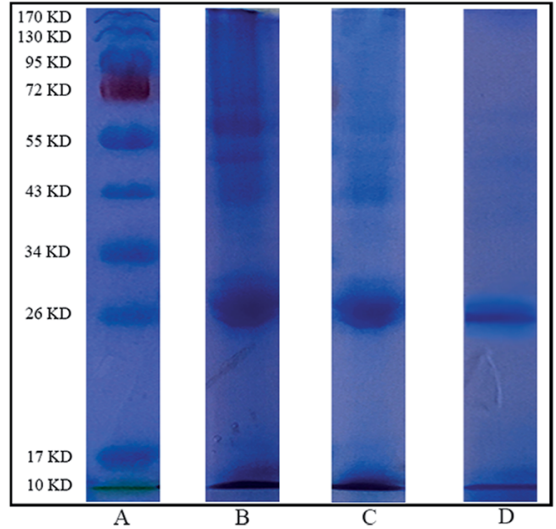

Fig. 10 Results of SDS-PAGE analysis: protein molecular weight marker $(A)$, porcine pancreas crude extract $(B)$, porcine pancreas crude extract after extraction (C) and eluate from $\mathrm{Fe}_{3} \mathrm{O}_{4} \mathrm{Q}$ CMC@PPDIL (D)

\subsection{Analysis of real sample}

As $\alpha$-Chy used in this work comes from porcine pancreas, the porcine pancreas crude extract was selected as the real sample in the practical part of this work. Referred to the literature, ${ }^{32}$ the porcine pancreas crude extract was prepared. The analytical result by sodium dodecyl sulfate polyacrylamide gel electrophoresis (SDS-PAGE) is demonstrated in Fig. 10. The specific band of $\alpha$-Chy in the extracted real sample (lane $\mathrm{C}$ ) obviously fades compared with the sample before extraction (lane $\mathrm{B}$ ), which proves that $\mathrm{Fe}_{3} \mathrm{O}_{4} @ C M C @ P P D I L$ indeed possesses extraction ability for $\alpha$-Chy. What's more, the clearer band of $\alpha$ Chy than that of other proteins in lane D implies that the purity of $\alpha$-Chy can be improved through the MSPE method based on $\mathrm{Fe}_{3} \mathrm{O}_{4} @ \mathrm{CMC} @ P P D I L$.
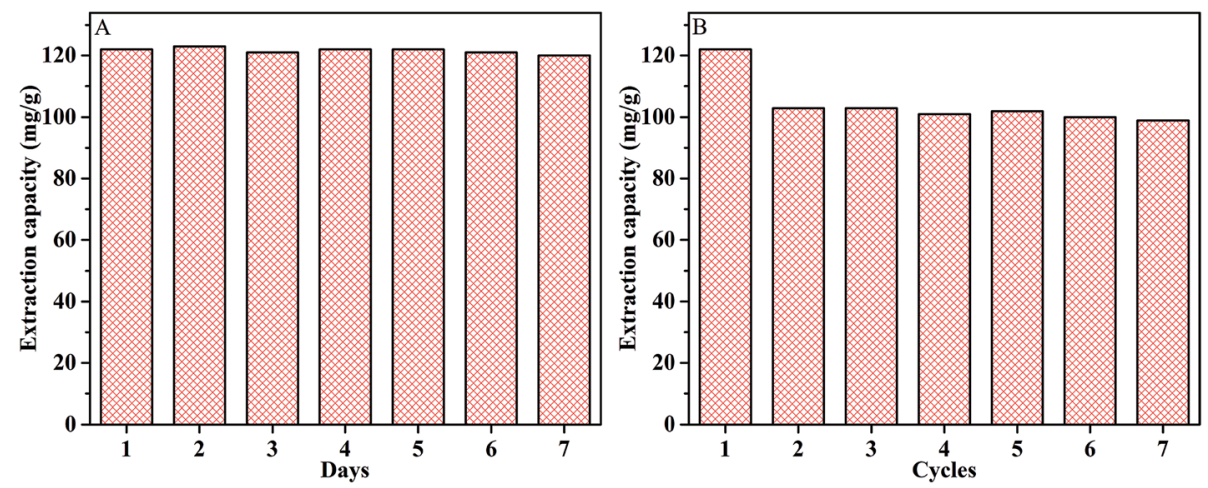

Fig. 9 Extraction stability (A) and reproducibility (B) of $\mathrm{Fe}_{3} \mathrm{O}_{4} \mathrm{QCMC}(\mathrm{CPPDIL}$. 


\section{Conclusions}

In this work, a novel MSPE method based on $\mathrm{Fe}_{3} \mathrm{O}_{4} @$ CMC@PPDIL nanomaterial was proposed and applied to the extraction of $\alpha$-Chy for the first time. Compared with the other three kinds of extractants, $\mathrm{Fe}_{3} \mathrm{O}_{4} @$ CMC@PPDIL nanocomposite possesses quite superior extraction capacity for $\alpha$-Chy. Besides, after the optimization of single factor experiments, both the extraction capacity and selectivity of $\mathrm{Fe}_{3} \mathrm{O}_{4} @ \mathrm{CMC} @ P P D I L$ for $\alpha$-Chy have been improved apparently. Moreover, the new MSPE method is proved to be of satisfactory stability, reproductivity and precision. And the result of real sample analysis suggests that the $\mathrm{Fe}_{3} \mathrm{O}_{4} @ C M C @ P P D I L-b a s e d$ MSPE method has potential application in pretreatment of biological samples.

\section{Conflicts of interest}

There are no conflicts to declare.

\section{Acknowledgements}

The authors greatly appreciate the financial supports by the National Natural Science Foundation of China (No. 21375035; No. 21675048) and the Foundation for Innovative Research Groups of NSFC (Grant 21521063).

\section{References}

1 G. Chen, Y. Xie, H. Zhang, P. Wang, H. Y. Cheung, M. Yang and H. Sun, RSC Adv., 2014, 4, 6560-6563.

2 P. Esakkiraj, B. Meleppat, A. K. Lakra, R. Ayyanna and V. Arul, RSC Adv., 2016, 6, 38611-38616.

3 T. Miyazawa, K. Tanaka, E. Ensatsu, R. Yanagihara and T. Yamada, J. Chem. Soc., Perkin Trans. 1, 2001, 87-94.

4 A. Szabo and M. Sahin-Toth, FEBS J., 2012, 279, 4283-4292.

5 H. Chen, Y. C. Zhu, R. J. Whitworth, J. C. Reese and M. S. Chen, Insect Biochem. Mol. Biol., 2013, 43, 701-711.

6 G. Telford, A. P. Brown, R. A. Seabra, A. J. Horobin, A. Rich, J. S. English and D. I. Pritchard, Br. J. Dermatol., 2010, 163, 523-531.

7 T. Miyazawa, S. i. Nakajo, M. Nishikawa, K. Hamahara, K. Imagawa, E. Ensatsu, R. Yanagihara and T. Yamada, J. Chem. Soc., Perkin Trans. 1, 2001, 82-86.

8 C. Kim and M.-J. Kim, Bull. Korean Chem. Soc., 2013, 34, 715716.

9 G. T. Wei, Z. Yang and C. J. Chen, Anal. Chim. Acta, 2003, 488, 183-192.
10 C. F. Poole, Trends Anal. Chem., 2003, 22, 362-373.

11 M. J. Trujillo-Rodríguez, V. Pino, E. Psillakis, J. L. Anderson, J. H. Ayala, E. Yiantzi and A. M. Afonso, Anal. Chim. Acta, 2017, 962, 41-51.

12 S. Ma, M. He, B. Chen, W. Deng, Q. Zheng and B. $\mathrm{Hu}$, Talanta, 2016, 146, 93-99.

13 M. Khan, E. Yilmaz, B. Sevinc, E. Sahmetlioglu, J. Shah, M. R. Jan and M. Soylak, Talanta, 2016, 146, 130-137.

14 E. Fernández, L. Vidal and A. Canals, J. Chromatogr. A, 2016, 1458, 18-24.

$15 \mathrm{~J}$. Chen and X. Zhu, Food Chem., 2016, 200, 10-15.

16 S. Mahpishanian and H. Sereshti, J. Chromatogr. A, 2016, 1443, 43-53.

17 Y. Tao, D. Su, Y. Du, W. Li, B. Cai, L. Di, L. Shi and L. Hu, RSC $A d v .$, 2016, 6, 109730-109741.

18 C. Wu, G. Zhu, J. Fan and J. Wang, RSC Adv., 2016, 6, 8642886435.

19 L. C. dos Reis, L. Vidal and A. Canals, Anal. Bioanal. Chem., 2017, 409, 2665-2674.

20 M. A. Habila, Z. A. ALOthman, A. M. El-Toni, S. A. Al-Tamrah, M. Soylak and J. P. Labis, Microchim. Acta, 2017, 1-7.

21 Y. Huang, Y. Wang, Y. Wang, Q. Pan, X. Ding, K. Xu, N. Li and Q. Wen, RSC Adv., 2016, 6, 5718-5728.

22 L. Liu, D. Liu, M. Wang, G. Du and J. Chen, Eur. Polym. J., 2007, 43, 2672-2681.

23 V. V. Alange, R. P. Birajdar and R. V. Kulkarni, J. Biomater. Sci., Polym. Ed., 2017, 28, 139-161.

24 I. Pacheco-Fernández, A. Najafi, V. Pino, J. L. Anderson, J. H. Ayala and A. M. Afonso, Talanta, 2016, 158, 125-133.

25 S. Wang, Q. X. Shi, Y. S. Ye, Y. Xue, Y. Wang, H. Y. Peng, X. L. Xie and Y. W. Mai, Nano Energy, 2017, 33, 110-123.

26 B. Wu, Z. W. Zhang, M. H. Huang and Y. Peng, RSC Adv., 2017, 7, 5394-5401.

27 Q. Yang, Y. Wang, H. Zhang, K. Xu, X. Wei, P. Xu and Y. Zhou, Talanta, 2017, 174, 139-147.

28 S. Sitthichai, C. Pilapong, T. Thongtem and S. Thongtem, Appl. Surf. Sci., 2015, 356, 972-977.

29 Q. P. Liu, X. D. Hou, N. Li and M. H. Zong, Green Chem., 2012, 14, 304-307.

30 J. Ge, Y. Hu, T. Zhang and Y. Yin, J. Am. Chem. Soc., 2007, 129, 8974-8975.

31 D. V. Volodkin, R. von Klitzing and H. Mohwald, Angew. Chem., Int. Ed. Engl., 2010, 49, 9258-9261.

32 K. Xu, Y. Wang, Y. Li, Y. Lin, H. Zhang and Y. Zhou, Anal. Chim. Acta, 2016, 946, 64-72. 